\title{
El papel de las administraciones públicas en el fomento de las empresas de inserción
}

\author{
The Role of Public Administration in the Development \\ of Insertion Firms \\ Marinete Alves Bayer \\ Observatorio de la Exclusión Social \\ y los Procesos de Inclusión en la Comunidad de Madrid \\ observatorioinclusion@trs.ucm.es
}

Recibido: 30/05/2011

Revisado: 14/07/2011

Aceptado: 28/11/2011

Disponible on line: 15/02/2012

\section{Resumen}

En este trabajo se resalta la importancia de las empresas de inserción, experiencias que asumen el reto de la integración de miles de personas en situación de exclusión social o en riesgo de la misma y constituyen una tipología específica entre las entidades de economía social y solidaria. Se agrupan en asociaciones autonómicas y están potenciando un sector que empieza a despegar en España. Su reconocimiento, a través de la Ley 44/2007, demuestra la relevancia que empiezan a tener dentro de las políticas activas de empleo, a pesar de un insuficiente y desigual apoyo que reciben y que es objeto del presente artículo. El objetivo de este artículo es aportar una panorámica sobre el tema que pueda contribuir a la investigación y trabajar con la perspectiva de conseguir mejores apoyos y un compromiso efectivo con las empresas de inserción por parte de las administraciones públicas.

Palabras clave: Exclusión, empresa de inserción, economía social, medidas de fomento, cláusulas sociales

\begin{abstract}
This article seeks to give the recognition due to the importance of Insertion Firms, pilot projects which take on the challenge of integrating thousands of people at risk of social exclusion and which comprise a specific type within social and non-profit entities. They come together in autonomous associations and are empowering a sector which is beginning to take off in Spain. Their recognition by Law No. 44/2007 demonstrates their importance in active employment policies, despite the insufficient and uneven support that they receive, which is described in this article. The topic is open to other deeper analyses, but the goal of this article is to give an overview and to draw some conclusions on which areas could continue to be researched with a view toward obtaining more support and commitment from public administration for Insertion Firms.
\end{abstract}

Keywords: Exclusion, insertion firms, Social economy, Means of development, Social clauses.

Referencia normalizada: Alves Bayer, M. (2012): «El papel de las administraciones públicas en el fomento de las empresas de inserción». Cuadernos de Trabajo Social, 25(1): 173-192.

Sumario: Introducción. 1. El marco de la Ley 44/2007 y el compromiso de las administraciones públicas. 2. Iniciativas de las administraciones autonómicas precedentes a la Ley 44/2007. 3. El proceso de las comunidades autónomas tres años después de la ley estatal. 4. El desarrollo de las empresas de inserción directamente proporcional a las medidas de fomento. 5. El caso de la comunidad autónoma de Madrid. 6. Conclusiones. 7. Referencias bibliográficas.

\section{Introducción}

Las empresas de inserción son un pequeño sector dentro de la economía social en España. La incorporación de la Federación de Asociaciones
Empresariales de Empresas de inserción (FAEDEI) a la Confederación Española de Economía Social (CEPES) ha sido un paso decisivo para su visibilización y clave para su reconocimiento. 
La Ley 44/2007 define la empresa de inserción como: «sociedad mercantil o sociedad cooperativa legalmente constituida que, debidamente calificada por los organismos autonómicos competentes en la materia, realice cualquier actividad económica de producción de bienes y servicios, cuyo objeto social tenga como fin la integración y formación sociolaboral de personas en situación de exclusión social como tránsito al empleo ordinario».

La aportación de estas empresas a la economía social y solidaria constituye una dimensión específica en la atención a situaciones de exclusión social: la creación de puestos de trabajo, la producción de bienes y servicios con criterios sociales, así como una experiencia de gestión empresarial.

En contrapartida, la creación de una actividad económica con mano de obra en proceso de formación supone también un coste añadido respecto al resto de las empresas. Es precisamente lo que se denomina sobrecoste laboral, lo que el sector plantea a las administraciones públicas como compensación necesaria a través de ayudas directas. La Memoria social 2009 de FAEDEI se refiere a este concepto:

Por término medio, un trabajador de inserción tiene para las empresas de inserción un coste salarial (salario bruto más cuotas de seguridad social a cargo de la empresa) de unos 16.500 euros anuales. La productividad laboral media para el conjunto de personal en las empresas de inserción estaría situada en unos 20.000 euros (aproximadamente la mitad de la empresa ordinaria).

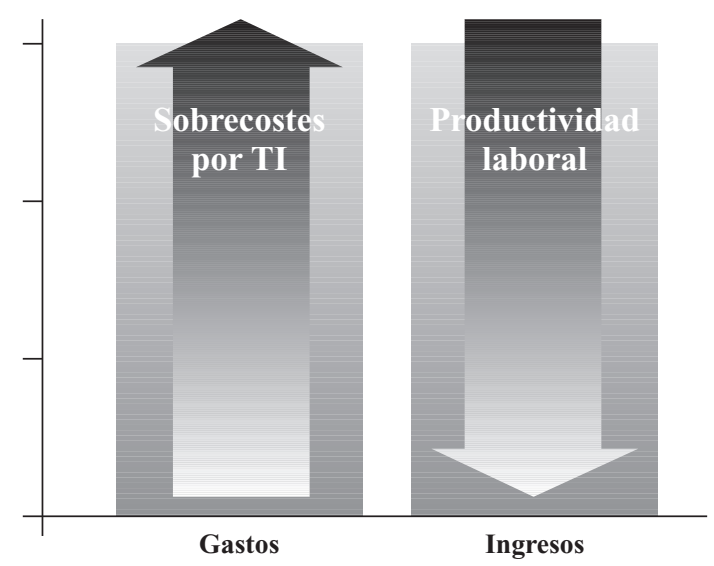

Figura 1. Sobrecoste laboral en la EI.
Por otro lado, el sobrecoste (...), ocasionado fundamentalmente por las personas de acompañamiento (para el desarrollo de itinerarios de inserción laboral, facilitando el aprendizaje de habilidades sociales y orientación laboral con el objetivo de favorecer el tránsito al empleo ordinario), las acciones formativas y el absentismo laboral actúan incrementando los gastos (Memoria Social de FAEDEI, 2009)

Teniendo en cuenta el coste salarial medio de estos profesionales (24.152 euros anuales) y estimando el número de trabajadores de inserción atendidos de media, podemos situar dicho sobrecoste en 2.400 euros por trabajador y año» (Idem).

El sector plantea a las administraciones públicas una serie de retos y necesidades sobre los que, a su vez, se está trabajando y colaborando desde hace cerca de veinte años y que son los siguientes:

1. Garantizar la legitimidad y la legalidad, de ahí la necesidad de una normativa de carácter estatal.

2. Asegurar las medidas necesarias de apoyo económico directo, a través de subvenciones a los puestos de trabajo, al acompañamiento social y a la consolidación del proyecto empresarial.

3. Reservar una cuota de mercado para las empresas de inserción.

El respaldo a estas tres líneas - normativa, apoyo económico y reserva de mercado - implica tanto a la Administración General del Estado como a los ayuntamientos, comunidades autónomas y diputaciones provinciales.

\section{El marco de la Ley $44 / 2007$ y el compro- miso de las administraciones públicas}

La Ley 44/2007, de 13 de diciembre, para la regulación del régimen de las empresas de inserción, fundamenta la necesidad de regular estas entidades en base a diferentes marcos de decisiones políticas a nivel estatal y europeo: para abordar los procesos de integración social a través del empleo de la población en edad laboral como fuente de ingresos, así como de toda una red de relaciones sociales que facilitan la integración; para señalar la eficacia de las políticas públicas de promoción de empleo y lucha contra la exclusión social como respuesta a dichas 
situaciones y para implicarse en las correspondientes soluciones. Este modelo de política social se basa fundamentalmente en la incorporación de nuevas formas de organización.

Asimismo en el ámbito comunitario, uno de los objetivos globales de la Estrategia europea de empleo es:

Consolidar la inclusión social, prevenir la exclusión del mercado laboral y apoyar la integración en el empleo de las personas desfavorecidas. Las directrices integradas establecidas bajo las tres prioridades de la Estrategia europea de empleo (oferta de mano de obra; adaptabilidad; capital humano) prestan una considerable atención a la promoción de un mercado laboral inclusivo.

En estas directivas se destaca la relevancia de las empresas de inserción dentro de las políticas activas de empleo, al considerar que el trabajo es una de las herramientas más importantes para el ejercicio de la ciudadanía y reconocer la necesidad de que las administraciones públicas diseñen políticas de lucha contra la exclusión social y se impliquen en las correspondientes soluciones.

El capítulo V de la Ley 44/2007 establece, en el artículo 16, el marco general de fomento y promoción de dichas empresas, en relación a: «el apoyo a la creación y mantenimiento de las mismas, en atención a que puedan cumplir su función social de facilitar la inserción de las personas en situación de exclusión en el mercado de trabajo ordinario» (art. 16.1); así como en cuanto a:

Ser beneficiarias de ayudas financieras para su adaptación a las previsiones de esta Ley, para su constitución, puesta en marcha y desarrollo de su actividad, así como en concepto de asistencia técnica, formación y contratación de técnicos para su gestión, y en concepto de actuaciones de $\mathrm{I}+\mathrm{D}+\mathrm{i}(\operatorname{art} .16 .2)$.

Las administraciones públicas se comprometen en sus respectivos ámbitos a promover las empresas de inserción, tal y como recoge la Ley 44/2007, que plantea como ayudas concretas para su promoción: a) bonificaciones a las cuotas de la Seguridad Social en los contratos de inserción; b) constitución, puesta en marcha y desarrollo de su actividad; c) Mantenimiento de puestos de trabajo para la inserción sociolaboral; d) Asistencia técnica; e) Inversión fija afecta a la realización de su objeto social; f) Formación y contratación de técnicos para su gestión; g) Subvenciones al servicio de acompañamiento social prestado; h) Actuaciones de $\mathrm{I}+\mathrm{D}+\mathrm{i}$; i) Promoción y funcionamiento de las entidades representativas de las empresas de inserción.

Curiosamente, la ley se refiere a las bonificaciones de la Seguridad Social, estableciendo una cuantía fija de 70,83 euros mensuales. Es el compromiso específico de la Administración General, dentro de sus competencias. En referencia a las demás líneas, determina que esas estructuras de inserción sociolaboral y sus entidades representativas «podrán» ser beneficiarias de ayudas y subvenciones. Asimismo respecto a las bonificaciones, en el sector se empieza a plantear la necesidad de una revisión de cuantías, debido al contexto de crisis de mediados de 2008.

Merece una atención especial la Disposición adicional primera, al abrir una puerta a la reserva de mercados. Así en relación a la Aplicación de la normativa de la Ley de Contratos del Sector Público, establece que las condiciones especiales de ejecución de los contratos «podrán incluir consideraciones relativas a la situación de la exclusión social de los trabajadores vinculados a la realización del contrato», de conformidad con lo dispuesto en la legislación de contratos del sector público.

\section{Iniciativas de las administraciones auto- nómicas precedentes a la Ley 44/2007}

Un total de doce comunidades autónomas han desarrollado algún tipo de medida respecto a las empresas de inserción con anterioridad a la Ley 44/2007. Ampliando el resumen que aparece en el cuadro 1, se desglosan algunos conceptos y especificidades de las medidas de regulación, establecimiento de registros y convocatoria de ayudas por las comunidades autónomas entre 1999 y 2007.

Navarra establece criterios que regulan los centros de inserción sociolaboral, figura que hasta el momento cumple las funciones que en otras comunidades autónomas tienen las empresas de inserción. Posteriormente se acercarán dichos criterios a los que marca la Ley 44/2007. 


\begin{tabular}{|c|c|c|c|c|c|c|c|c|}
\hline \multirow[b]{2}{*}{$\begin{array}{l}\text { Comunidad } \\
\text { Autónoma }\end{array}$} & \multirow[b]{2}{*}{$\begin{array}{l}\text { Medida o normativa } \\
\text { publicada }\end{array}$} & \multirow[b]{2}{*}{ Objetivo } & \multicolumn{6}{|c|}{ Medidas de Fomento establecidas } \\
\hline & & & 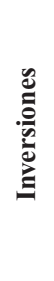 & 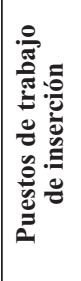 & 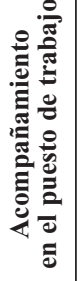 & 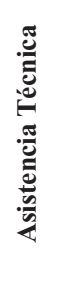 & 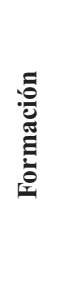 & $\stackrel{0}{0}$ \\
\hline Navarra & Decreto $130 / 1999$ & $\begin{array}{l}\text { Regulación del empleo social } \\
\text { protegido, inserción laboral en } \\
\text { empresas, proyectos de trabajo } \\
\text { individual y ayudas a los centros } \\
\text { de inserción sociolaboral. }\end{array}$ & & & & & & \\
\hline País Vasco & Decreto $305 / 2000$ & $\begin{array}{l}\text { Regulación empresas de inser- } \\
\text { ción y creación del registro }\end{array}$ & & & & & & \\
\hline Aragón & Decreto 33/2002 & $\begin{array}{l}\text { Regulación empresas de inserción } \\
\text { y creación del programa ARIN- } \\
\text { SER de ayudas }\end{array}$ & & & & & & \\
\hline Cataluña & Ley $27 / 2002$ & \multirow{3}{*}{ Regulación empresas de inserción } & & & & & & \\
\hline Canarias & Decreto 32/2003 & & & & & & & \\
\hline Madrid & Decreto 32/2003 & & & & & & & \\
\hline La Rioja & Ley $7 / 2003$ & $\begin{array}{l}\text { Ley de inserción, dentro de la } \\
\text { cual se reconoce y define la fi- } \\
\text { gura de la empresa de inserción }\end{array}$ & & & & & & \\
\hline Baleares & Decreto 60/2003 & $\begin{array}{l}\text { Regulación empresas de inser- } \\
\text { ción y creación del registro }\end{array}$ & & & & & & \\
\hline $\begin{array}{l}\text { Comunidad } \\
\text { Valenciana }\end{array}$ & Ley $1 / 2007$ & Regulación empresas de inserción & & & & & & \\
\hline $\begin{array}{l}\text { Castilla } \\
\text { y León }\end{array}$ & Decreto $34 / 2007$ & \multirow{2}{*}{$\begin{array}{l}\text { Regulación empresas de inser- } \\
\text { ción y creación del registro }\end{array}$} & & & & & & \\
\hline Galicia & Decreto $156 / 2007$ & & & & & & & \\
\hline Murcia & $\begin{array}{l}\text { R e s o } 1 \text { u c i ó n } \\
27 / 07 / 2007\end{array}$ & $\begin{array}{l}\text { Convocatoria de subvenciones } \\
\text { para empresas de inserción }\end{array}$ & & & & & & \\
\hline
\end{tabular}

Cuadro 1. Normativa y convocatorias anteriores a la Ley 44/2007, que mencionan o reconocen las empresas de inserción. Fuente: elaboración propia.

Al establecer las líneas de subvención, favorece criterios de inversiones de capital fijo relacionados con la creación y mantenimiento de puestos de trabajo de inserción. La subvención por puesto de trabajo se fija en 80 por cien del salario mínimo interprofesional por jornada completa e incluye como asistencia técnica la subvención para técnicos de acompañamien- to social y a la producción, además de estudios de mercado y planes de viabilidad.

El Decreto 305/2000 del País Vasco regula la calificación y el procedimiento de acceso a las empresas de inserción por parte de las personas con especiales dificultades de incorporación al mercado laboral ordinario. Asimismo la Orden, publicada en el BOPV de 27 de diciem- 
bre de 2002, establece seis líneas de ayudas. El 14 de abril de 2003 se publicó la primera convocatoria que pondría en práctica los compromisos de la Orden de bases.

El Decreto 33/2002 de Aragón, además de la regulación de las empresas de inserción y de la creación del registro, establece a través del programa ARINSER (Aragón Inserta) un marco de ayudas con varias líneas, incluyendo una subvención por puesto de inserción en el mercado ordinario y otra para la contratación de director o gerente.

En Cataluña, la Ley 27/2002, además de definir sus características y regular las actividades, crea también el registro que se regirá por del Decreto 277/2003 y establece líneas de medidas de formación de cuadros directivos y de gestión, difusión de las actividades relacionadas con el colectivo del que quiere conseguirse la inserción, estudio de los puestos de trabajo a cubrir, medidas de acompañamiento para la tutorización por medio de un técnico o técnica de inserción laboral, y fomento de procesos de creación de empresa de inserción. A demás en la Orden TRE/120/2007, de 17 de abril, se aprueban las bases reguladoras para la concesión de ayudas, que se fija en 40por ciento de los costes salariales derivados de la contratación del trabajador en proceso de inserción, con un tope de 4.200,00 euros/año, a tiempo completo.

En Canarias, el Decreto 32/2003 establece, entre otras, ayudas para la incorporación al autoempleo o al empleo asalariado ordinario, aunque la primera convocatoria es la de septiembre de 2005. El Decreto 32/2003 de Madrid establece el marco general y se publican la Orden de creación y normas de funcionamiento del registro, acompañada de una convocatoria de ayudas para 2003. El Decreto establece ocho posibles líneas de ayudas, entre las que se contempla la incorporación al autoempleo o al empleo asalariado ordinario. En el caso de La Rioja, la Ley 7/2003 de inserción sociolaboral define las empresas de inserción en su capítulo IV (arts. 21-24). Crea posteriormente el registro (Decreto $2 / 2006$ ) y la Orden de 25 de septiembre 2007 establece algunas ayudas, aunque no se vuelve a convocar desde entonces.

En Baleares, el Decreto 60/2003 establece varias líneas de ayudas, orientadas a la crea- ción de empresas de inserción, asistencia técnica y la incorporación de trabajadores de inserción al autoempleo y al empleo ordinario. $\mathrm{La}$ Comunidad valenciana, al regular las empresas de inserción en enero 2007, establece tres líneas de ayudas, aunque no las convoca hasta el año 2010. Galicia, la última comunidad autónoma en regular las empresas de inserción con anterioridad a la Ley 44/2007, establece ocho líneas de ayudas. El Decreto de Castilla y León regula las empresas de inserción y crea el registro, pero no establece líneas de ayudas. Finalmente, Murcia, sin haber regulado las empresas de inserción, convoca subvenciones por primera vez en julio 2007.

El camino recorrido antes de 2007 demuestra, en primer lugar, el compromiso de las entidades sin ánimo de lucro y de las propias empresas de inserción que se han ido creando y desarrollando desde mediados de los años 1980. En otras palabras, la apuesta de las entidades promotoras es anterior a las medidas de fomento. Por otro lado, la Ley 44/2007 recoge muchos de los contenidos y de las prácticas que se venían realizando en las comunidades autónomas, reconociendo el trabajo conjunto realizado entre administraciones e iniciativa social para consolidar las empresas de inserción. El conjunto de estas normativas supone: reconocimiento y regulación del sector; establecimiento de registros autonómicos y convocatorias de ayudas.

Cada comunidad autónoma sigue esquemas normativos, ritmos y calendarios diversos, a pesar de que las definiciones y argumentaciones favorables al soporte de estas iniciativas son similares y proporcionan la base adecuada para llegar a la Ley 44/2007. En cuanto a ritmos podemos observar las siguientes situaciones:

Ejemplo 1. Cataluña regula las empresas de inserción a través de la Ley $27 / 2002$, que se publica en enero 2003 y solamente en noviembre se aprueba el Decreto 277/2003 de regulación de funcionamiento del registro que dará cauce al reconocimiento de las mismas, con lo cual, empiezan a registrarse en 2004 (gráfico 1).

Ejemplo 2. La Comunidad canaria hace público el Decreto 32/2003 a finales de marzo, completa la regulación del registro hacia finales de 2004 y solamente en septiembre 2005 convoca las primeras ayudas. 


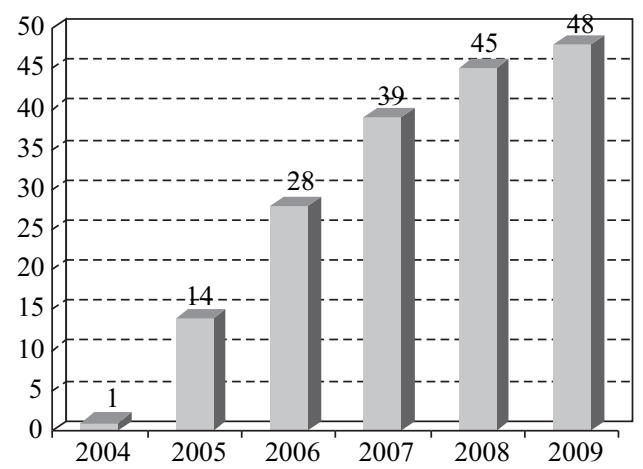

Gráfico 1. Empresas de inserción registradas año a año, entre 2004 y 2009. Fuente: Generalitat de Cataluña.

Ejemplo 3. Al Decreto 32/2003 de Madrid, publicado en marzo, le sigue tres meses después la norma reguladora del registro y de la primera convocatoria de ayudas (sin demasiado valor histórico, porque después de la primera convocatoria se paraliza el proceso durante 4 años).

Otras comunidades autónomas mostraron interés en la regulación o alguna convocatoria de ayudas, pero no dieron continuidad al proceso: es el caso de Baleares y La Rioja o de la Comunidad valenciana, aunque esta última publica la Ley ya en 2007. El caso de Murcia tiene la peculiaridad de haber publicado una convocatoria de ayudas sin que existiera una regulación como tal.

Una vez más, los ritmos de este proceso y su consolidación están estrechamente relacionados con la existencia de un sector organizado y coordinado en cada territorio, aunque también y en gran medida con la importancia que se ha dado desde la Administración a las políticas sociales y al papel de las empresas de inserción dentro de las mismas.

\section{El proceso de las comunidades autóno- mas tres años después de la ley estatal}

En 2010 tres comunidades autónomas publicaron nuevos decretos reguladores: Castilla-La Mancha, Andalucía y Extremadura. En los territorios donde aún no existe regulación o hay poca representatividad de experiencias o no existe una asociación territorial específica. A través de el cuadro 2 se puede ver una panorá-

\begin{tabular}{|l|l|}
\hline Comunidad Autónoma & Normativa de referencia \\
\hline Andalucía & Decreto 193/2010 \\
\hline Aragón & Decreto 128/2009 \\
\hline Asturias $\left(^{*}\right)$ & Resolución de 22-12-2008 \\
\hline Baleares & Decreto 60/2003 \\
\hline Canarias & Decreto 137/2009 \\
\hline Castilla La Mancha & Decreto 22/2010 \\
\hline Castilla y León & Decreto 34/2007 \\
\hline Cataluña & Ley 27/2002 \\
\hline Comunidad Valenciana & Ley 1/2007 \\
\hline Extremadura & Decreto 78/2010 \\
\hline País Vasco & Decreto 182/2008 \\
\hline Galicia & Decreto 156/2007 \\
\hline La Rioja & Ley 7/2003 \\
\hline Madrid & Decreto 32/2003 \\
\hline Navarra & Decreto Foral 130/1999 \\
\hline $\begin{array}{l}\text { (*) Se incluye Asturias, porque se crea el registro a través de } \\
\text { la Resolución de 2008. No se incluye Murcia, porque man- } \\
\text { tiene únicamente convocatoria de ayudas, pero no ha regula- } \\
\text { do las Empresas de inserción. }\end{array}$ \\
\hline
\end{tabular}

Cuadro 2. Normativa por comunidad autónoma. Mayo 2011. Fuente: elaboración propia.

mica de la regulación en las diferentes autonomías, teniendo en cuenta, que las tres formas de apoyo de las administraciones públicas, que hemos venido señalando (regulación, registro y ayudas), no siempre se articulan con la misma norma. Por otro lado, el hecho de contar con una normativa autonómica con anterioridad a la Ley 44 de 2007 supone tener que adaptar los aspectos que se diferencian.

Si bien esta Ley cumple un papel fundamental al establecer un marco, características comunes, un registro estadístico y una bonificación en el ámbito de las competencias del Estado, está en manos de las administraciones autonómicas el apoyo concreto y la posibilidad de asegurar las principales medidas de fomento, ya que las competencias en la materia están transferidas a las comunidades autónomas. Para ello, se ha ido estableciendo un marco de ayudas, tal y como se puede apreciar en 


\begin{tabular}{|l|l|c|}
\hline \multicolumn{1}{|c|}{ Comunidad autónoma } & \multicolumn{1}{|c|}{ Convocatoria } & $\begin{array}{c}\text { Dotación presupuestaria } \\
\text { (euros) }\end{array}$ \\
\hline Aragón & Resolución 25/02/2011 & $595.881,65$ \\
\hline Canarias & Resolución 29 de junio 2010 & $685.666,30$ \\
\hline Castilla y León & Orden EYE/2392/2009 & $200.000,00$ \\
\hline Cataluña & TRE/805/2009 - TRE/113/2010 & $4.399 .352,87$ \\
\hline Comunidad Valenciana & Orden 31/2010 & $250.000,00$ \\
\hline Galicia & Orden 26/05/2010 & $375.000,00$ \\
\hline Madrid & Orden 2141/2010 & $600.000,00$ \\
\hline Murcia & Orden 25/05/2010 & $327.000,00$ \\
\hline Navarra & Decreto Foral 130/1999, abierta todo el año & \\
\hline País Vasco & Orden 30/04/2010 & $10.281 .280,00$ \\
\hline
\end{tabular}

Tabla 3. Última convocatoria de ayudas. Fuente: elaboración propia.

el cuadro 3, con las respectivas órdenes o resoluciones:

Por otro lado, los diferentes decretos y órdenes de bases definen para cada comunidad autónoma líneas de ayudas (algunas ya existían con anterioridad a la Ley 44/2007), que dan mayor o menor estabilidad al sector, dada la necesidad de cobertura de los sobrecostes que se reclaman. El cuadro 4 es una panorámica de dichas líneas:

Las líneas de ayudas coinciden en la mayor parte de las comunidades, aunque se diferencian en cuantías y conceptos:

- Hay una gran diversidad en el concepto de puesto de inserción o contrato de inserción: en base a un porcentaje del salario mínimo interprofesional o del Indicador de renda de suficiència, a un porcentaje del coste salarial o a un importe fijo con cuantías muy variadas.

- El acompañamiento social se fija sobre todo en base a una cuantía por puesto de inserción, con ratios en relación al número de trabajadores acompañados. Hay notables diferencias entre los máximos fijados por las distintas comunidades. Se entiende que es una función muy específica en la empresa de inserción y para la que se requiere apoyo porque es uno de los factores claves de sobrecoste. Sin embargo, en el caso de las empresas pequeñas difícilmente se alcanzan los topes fijados por las convocatorias ya que las ratios quedan muy lejanas.
- También se viene subvencionando el acompañamiento a la producción y a la comercialización, con ratios similares al acompañamiento social.

- El apoyo a la contratación de personal gerente o directivo es minoritario en el conjunto de las comunidades.

- Hay apoyos para la creación de nuevas empresas de inserción, básicamente a través de la subvención a los estudios de mercado, planes de viabilidad, gastos de constitución y primeros meses de funcionamiento.

- En la línea de inversiones los criterios varían, asociándolas en algunos casos a la creación de nuevos puestos de trabajo de inserción.

- En asistencia técnica los conceptos son variados: asesoramiento, certificaciones de calidad, mejoras en la gestión, auditorías sociales o de gestión.

Finalmente hay una serie de otras líneas de ayudas:

- Formación: aparece como apoyo en especie, donde la Administración correspondiente asume el compromiso de ofertarla y se refiere a la formación de la plantilla de estructura de la empresa de inserción. En otros casos se subvenciona en cuantías.

- Incorporación al mercado ordinario: aparecen medidas de apoyo tanto de cuantías ingresadas a la empresa de inserción por per- 


\begin{tabular}{|c|c|c|c|c|c|c|}
\hline 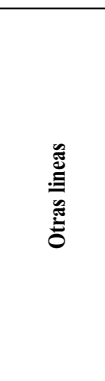 & 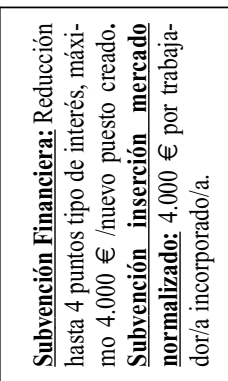 & 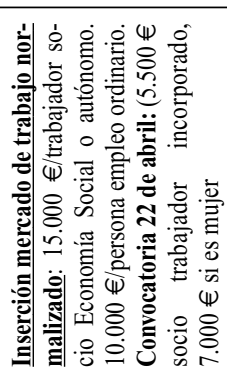 & & 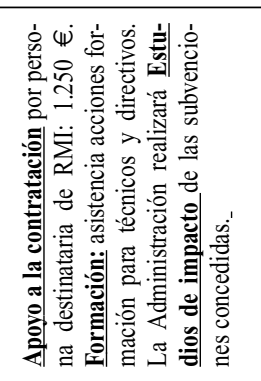 & 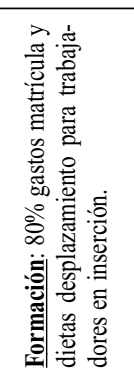 & 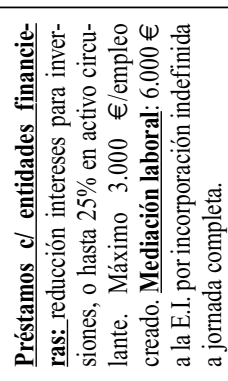 \\
\hline 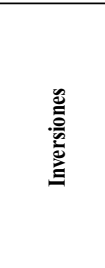 & 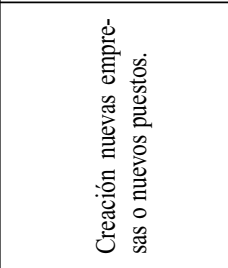 & 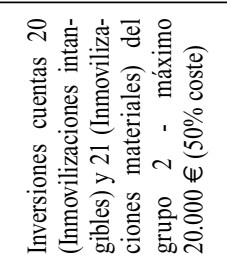 & & & 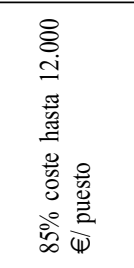 & 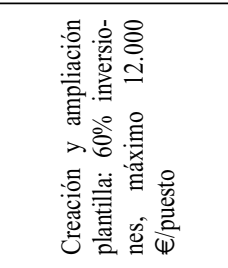 \\
\hline 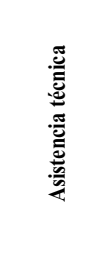 & 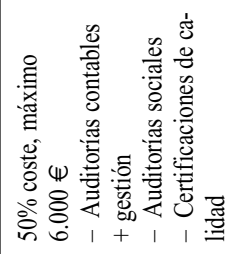 & & & & 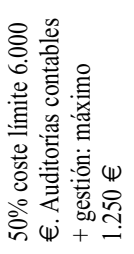 & \\
\hline 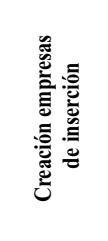 & 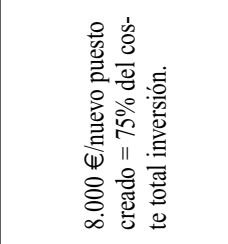 & 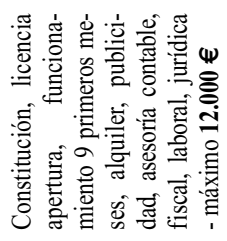 & & & 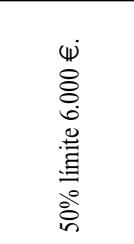 & \\
\hline 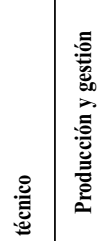 & 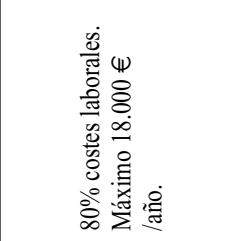 & 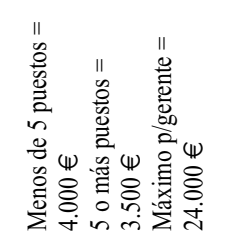 & & 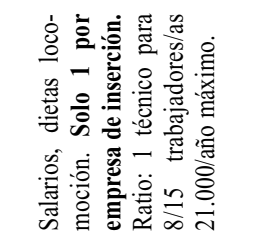 & 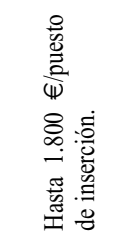 & 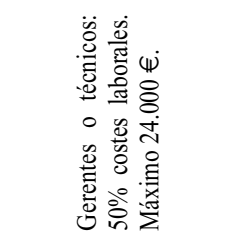 \\
\hline 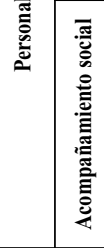 & 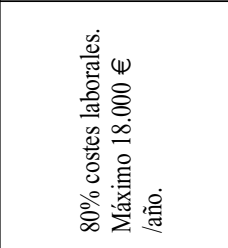 & 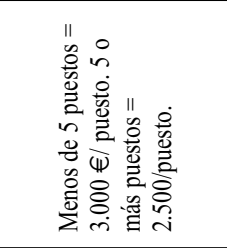 & & 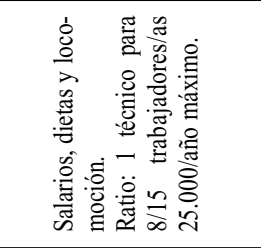 & 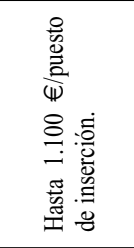 & 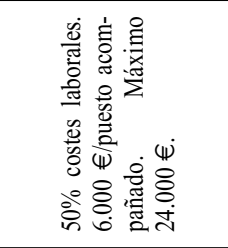 \\
\hline 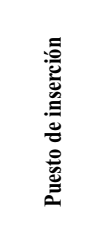 & 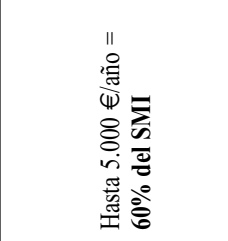 & 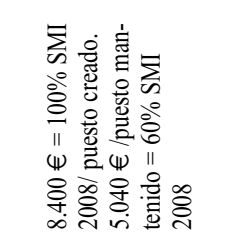 & 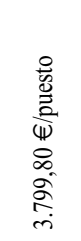 & 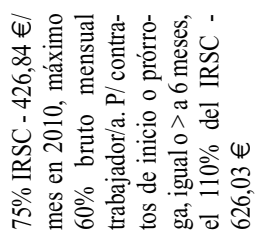 & 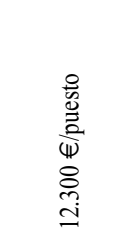 & 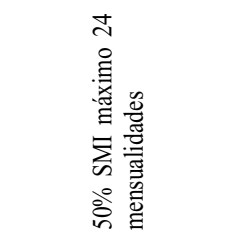 \\
\hline 离 & 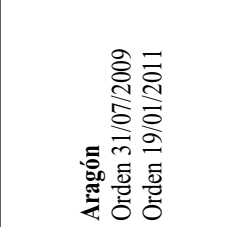 & 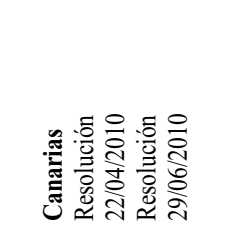 & 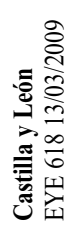 & 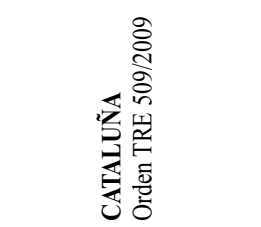 & 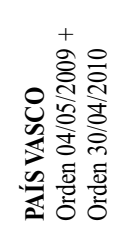 & 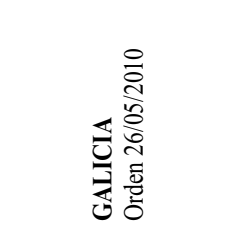 \\
\hline
\end{tabular}




\begin{tabular}{|c|c|c|c|c|}
\hline 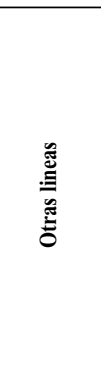 & 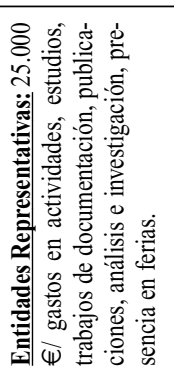 & & 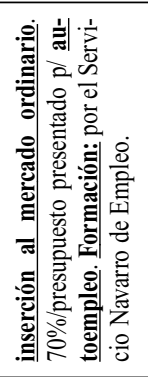 & 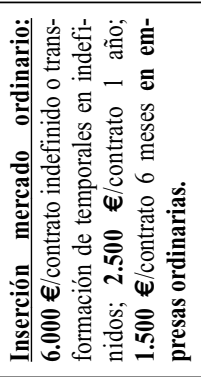 \\
\hline 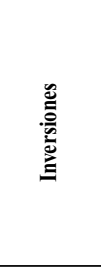 & 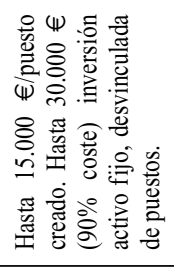 & & 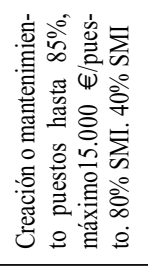 & \\
\hline 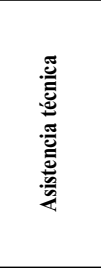 & 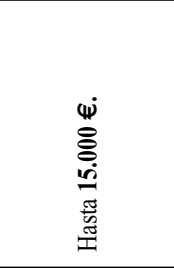 & \multirow{2}{*}{ 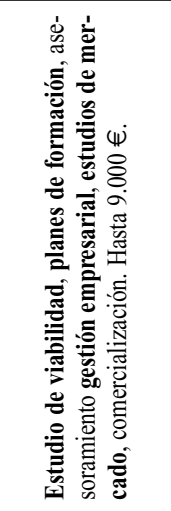 } & & \multirow{2}{*}{ 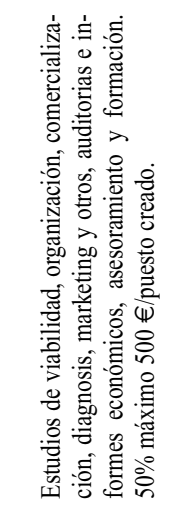 } \\
\hline 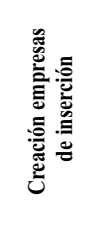 & 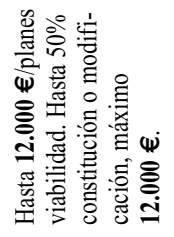 & & 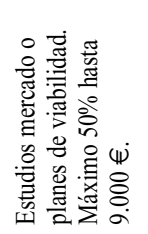 & \\
\hline \multirow{2}{*}{ 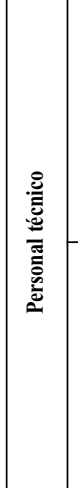 } & 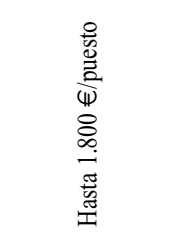 & 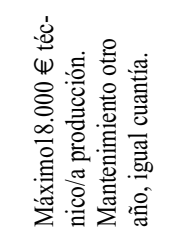 & \multirow{2}{*}{ 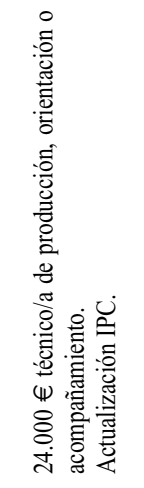 } & \multirow{2}{*}{ 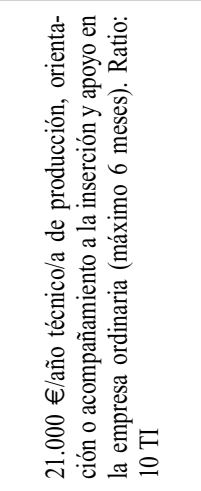 } \\
\hline & 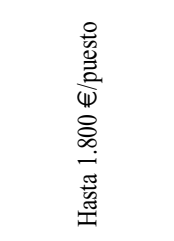 & 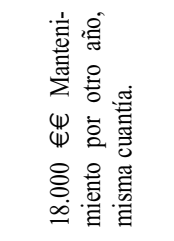 & & \\
\hline 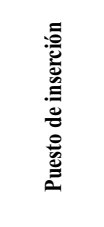 & $\begin{array}{l}\frac{8}{8} \\
\frac{2}{2} \\
\frac{1}{4} \\
0 \\
0 \\
0 \\
0\end{array}$ & 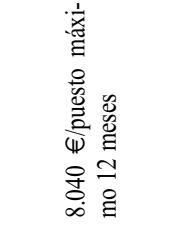 & 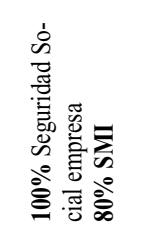 & 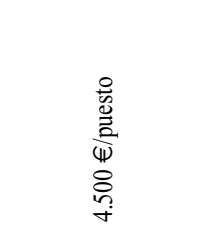 \\
\hline 奀 & 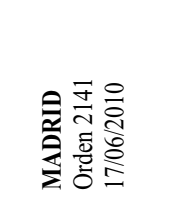 & 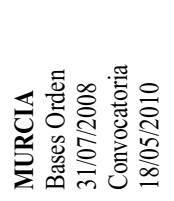 & 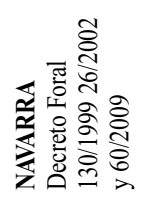 & 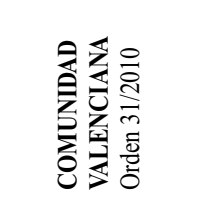 \\
\hline
\end{tabular}


sona que se incorpora a la empresa ordinaria o al autoempleo, como algunos casos de subvención a la empresa que contrata.

- Aparece algunos casos de subvenciones financieras o de apoyo a través de convenios de la Administración con entidades financieras para reducir intereses.

- Se incluye, en el caso de Cataluña, un concepto de estudio de impacto a realizar por la Administración sobre resultados conseguidos a través de las subvenciones.

- Finalmente, Madrid incluye en la convocatoria de 2010 una línea dotada con 25.000 euros para entidades representativas del sector, asociada a actividades de apoyo y fomento.

\subsection{Dotaciones presupuestarias:}

Las dotaciones de las convocatorias vienen soportadas por el Fondo Social Europeo y los importes varían en función de cada comunidad autónoma. En la mayoría de los casos se han publicado con las órdenes o resoluciones de ayudas. Una vez que se conceden las subvenciones, se publican resoluciones con lo que efectivamente reciben las empresas de inserción o las entidades promotoras según el caso.

Algunas convocatorias no hacen pública la dotación presupuestaria correspondiente. Por otro lado, la posibilidad de agotar tales presupuestos depende de los criterios de subvención, es decir, si un puesto de trabajo de inserción en el País Vasco puede alcanzar un máximo de subvención de 12.300 euros, en el caso de la Comunidad valenciana es de 4.500 euros. Por estas diferencias se explica en parte el no agotamiento de determinadas reservas de presupuesto en algunas convocatorias. Queda patente un nivel de desigualdad que retomaremos más adelante.

\subsection{Convocatorias de subvenciones de di- putaciones y ayuntamientos}

Es interesante mencionar dos ejemplos de convocatorias específicas de subvenciones para empresas de inserción de ámbitos distintos a las comunidades autónomas: El caso de la diputación de Málaga: la convocatoria ha estimulado la creación de nuevas de estas empresas e incluso se ha creado una asociación provincial que agrupa las iniciativas de la región. Otra experiencia conocida ha sido la convocatoria del Ayuntamiento de Gijón en 2005, que no se volvió a repetir, seguramente por falta de demanda.

\subsection{Cláusulas sociales y mercados tutelados}

Dentro de las medidas de fomento de las empresas de inserción, las «cláusulas sociales» pueden ser más importantes que las propias ayudas directas para, considerando que estas empresas apuestan claramente por la acción empresarial como su base de sostenimiento principal. El fomento de este tipo de medidas depende de las administraciones públicas (general, autonómicas, provinciales, municipales). Hay ejemplos de aplicación de cláusulas sociales en muchos municipios y en algunas comunidades (Cataluña, País Vasco, Principado de Asturias, Navarra, etc.), actuaciones que han significado para estas empresas un crecimiento importante en su volumen de facturación y en la generación de puestos de trabajo de personas en situación de exclusión.

\section{El desarrollo de las empresas de inser- ción en el territorio directamente proporcio- nal a las medidas de fomento}

La Memoria social 2009 de FAEDEI, anteriormente citada, refleja la existencia de $193 \mathrm{em}$ presas de inserción, distribuidas por casi todas las comunidades autónomas: dos territorios, Cataluña y País Vasco, se acercan al 50 por cien del número total de iniciativas, dato que releva su relación con la existencia de medidas regulares de apoyo al sector en las mismas. Otras, como Madrid, Andalucía, Aragón, Castilla y León o Canarias, a pesar de que cuentan con un número medio más pequeño de experiencias, mantienen una presencia activa con sus agrupaciones territoriales, siempre al frente de una lucha continuada por asegurar un contexto favorable al crecimiento del sector. Sin embargo, entre estos últimos hay notables diferencias de crecimiento.

El impulso inicial de los años 1990, que culmina con la creación de FEDEI en 1998, surge de la apuesta de muchas entidades sociales que vieron en las empresas de inserción una oportunidad, como actuación complementaria con otras que venían realizando, para dar respuestas a las necesidades de inserción social de muchas personas.

Además de la motivación inicial y la combinación de recursos de las entidades sociales, 
en algunos territorios las administraciones públicas las consideraron como un instrumento eficaz en la lucha contra la exclusión social y decidieron apoyarlas. Tanto los preámbulos de las normativas autonómicas como los textos históricos del sector describen planes y programas desde los años 1990, como origen de muchas iniciativas que todavía se mantienen actualmente. Gracias al esfuerzo de dichas entidades y de esos apoyos iniciales, muchas de estas empresas se han mantenido sin apoyos para su fomento durante años.

Las diferentes velocidades de crecimiento de estas empresas en los territorios tienen relación con las decisiones políticas, las políticas sociales y la buena coordinación con el sector. En el caso del País Vasco la decisión de la Administración Pública, al regular y establecer las medidas de fomento, muestra como resultado un crecimiento continuo desde 2003, hasta alcanzar cerca de 50 iniciativas en 2009-2010. El ejemplo de Cataluña, que en términos normativos es algo posterior, sigue el mismo camino de compromiso de la Administración, con el establecimiento de programas que repercutirían directamente en su crecimiento. En ambos casos las cláusulas sociales y la reserva de mercado para este tipo de empresas han sido decisivas.

La aprobación de la Ley 44/2007 ha dado un nuevo impulso y desde entonces unas comunidades han reformulado y actualizado sus normativas, otras han decidido por fin regularlas y se abren vías para convocatorias de subvenciones. Todo ello tiene un efecto positivo sobre la motivación de las potenciales entidades promotoras de estas empresas para asumir el reto de sumarse a este proceso.

En la actualidad hay un movimiento favorable para las empresas de inserción en varias comunidades, apuntando hacia un incremento en el número de iniciativas. Queda para muchas de ellas el reto de crecimiento interno como proyecto empresarial y en número de puestos de trabajo.

\section{El caso de la comunidad autónoma de Madrid}

\subsection{Proceso de gestación}

En Madrid las primeras experiencias de las empresas de inserción nacen a finales de los años 1980, pero es a lo largo de la década de 1990 cuando un grupo de entidades sociales, con el apoyo de la Consejería de Integración Social (proyectos de Ingreso Madrileño de Integración), deciden preparar una serie de iniciativas y crear una asociación de ámbito autonómico para agruparlas, apoyarlas $y$ desarrollarlas. La apuesta suponía formar a un grupo de personas para diseñarlas, hacerlas viables y gestionarlas.

Las primeras iniciativas surgieron de proyectos formativos-ocupacionales en torno al trabajo existente en las entidades, que dio lugar a actividades como: encuadernación, limpieza, jardinería, carpintería, recuperación y reciclaje, confección u hostelería. Se recoge, en las primeras sistematizaciones de estas empresas madrileñas, una interesante variedad de perfiles de población atendida y también territorial, sobre todo en relación a barrios y distritos de la capital (Basagoiti Rodríguez, 1998).

A mediados de la década de 2000, en paralelo con iniciativas de éxito en otras comunidades, algunas entidades sociales de Madrid participaron o impulsaron redes en torno a proyectos de la iniciativa europea Equal, incluyendo entre sus objetivos específicos la creación de nuevas empresas de inserción, a través de las cuales se dio impulso a la economía social. Algunas experiencias vieron la luz, pero no necesariamente se mantuvieron.

La Memoria social de 2007 de la Asociación Madrileña de Empresas de inserción (AMEI) incluye un listado de iniciativas creadas entre 1984 y 2007, de las cuales muy pocas se mantienen como tales y la mayoría han dejado de funcionar. Las entidades sociales promotoras de aquellas iniciativas mantuvieron actuaciones en torno a la inserción sociolaboral -formación, intermediación y orientación - trabajando muchas de ellas en itinerarios personalizados, pero no con tales. Este repliegue de las promotoras y la lenta incorporación ha sido un factor de estancamiento. Sin embargo, una de las claves de esta pérdida de iniciativas por el camino y del lento crecimiento en Madrid se encuentra en la falta de apoyos especificos para este tipo de empresas.

AMEI nació con la perspectiva de buscar la aprobación de una ley de empresas de inserción en la Comunidad de Madrid, tras amplios 


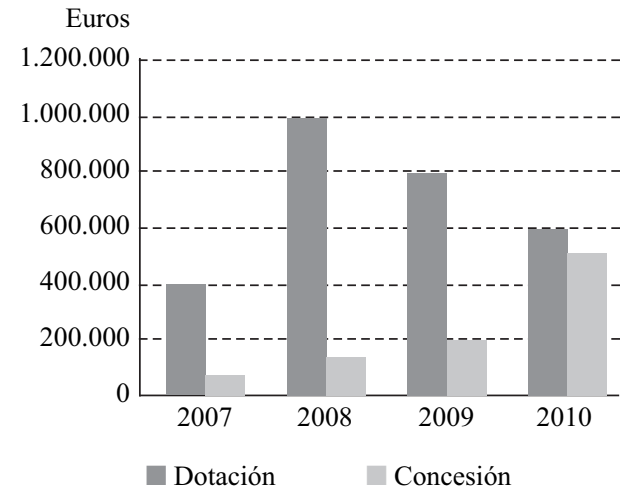

Gráfico 2. Comvocatorias de subvenciones Comunidad de Madrid. Fuente: Comunidad de Madrid.

debates sobre un borrador entre los ámbitos interesados y un proceso que quedó interrumpido. En 2003 se logró aprobar el Decreto $32 / 2003$, que sigue siendo hasta el momento la referencia normativa existente. Tres meses después de su promulgación, la Consejería de Trabajo publicó una convocatoria de subvenciones, a la que se presentaron muy pocas estas de empresas, debido a las exigencias burocráticas y los plazos para los que la mayoría no estaba preparada. Varias de ellas no contaban con contratos de inserción reconocidos y no podían acceder al registro.

En los años sucesivos no se convocaron ayudas. Los cambios de gobierno influyeron en la incertidumbre del sector, la interlocución se hizo difícil durante un largo período, pero, finalmente, la creación de la Dirección General de Empleo, que acoge dentro de la Consejería de Empleo y Mujer a los Centros Especiales de Empleo y las empresas de inserción, ha permitido un diálogo fluido y culminado en 2007 con la primera convocatoria de esta nueva etapa. Para Madrid, por lo tanto, las ayudas a estas empresas inician su ciclo en 2007 , estando en la cuarta convocatoria en 2010.

Al comparar las órdenes de 2007, 2008, 2009 y 2010 vemos que en cuatro años se han ampliado las líneas de subvención. Madrid es, junto con Aragón, Galicia y el País Vasco, la comunidad autónoma con más variedad de conceptos subvencionables. Además introduce en la Orden 2010 una vía de financiación de la agrupación territorial, lo que la diferencia de las demás comunidades.
En cuanto a dotación presupuestaria, la evolución es positiva de 2007 a 2008, pasando de 400.000 euros a 997.000 euros, para luego disminuir en 2009 a 795.000 euros y, de nuevo, en 2010 a 600.000 euros. Por otro lado, los importes efectivamente concedidos son muy inferiores, apenas superan el 18 por cien del presupuesto disponible para las 3 primeras convocatorias, para luego equilibrarse en 2010 (en los 4 años se concede el 32,7 por cien del crédito presupuestario). Se conoce que la demanda en 2010 supera con creces el crédito disponible para la convocatoria.

Nos detenemos en la fecha de cada convocatoria de los tres primeros años - noviembre, octubre y de nuevo noviembre - para resaltar una mejora al publicarse la Orden de 2010 a principios de julio. Cuando menos, es una circunstancia distinta de otras convocatorias públicas de subvenciones y de este tipo de convocatoria en otras comunidades. Sin embargo, el plazo de presentación es muy corto, un mes desde su publicación, en comparación con otras comunidades (algunas abiertas todo el año, otras de 6 meses o se mantiene hasta octubre y luego vuelve a abrirse).

\subsection{Cierre de empresas de inserción y su relación con el marco de ayudas:}

Desde 2003 algunas empresas de inserción históricas y otras de reciente creación decidieron cerrar sus puertas, en algunos casos incluso antes de haberse registrado como tales de la Comunidad de Madrid: Zoco Iniciativas de Empleo, Biomueble, Altea Limpiezas, ASMUM, Jardinería Multicolor, Ecoirirs, Lavadero de coches (Impulso Solidario), Romihilo, Trabajando Aprendemos (renuncia al registro), Emaus M-Sur, La Perla - Iniciativa Comunitaria por el Empleo, Ibermanip (sin información, pero registrada provisionalmente en 2009), ED Escenografía (registrada provisionalmente en 2009) o Ecolínea (suspende la actividad en 2011). Entre los factores que han llevado al cese de actividades se destaca la falta de solvencia económica.

Desde el año 2003, en el que se crea el registro en la Comunidad de Madrid, se han constituido ocho nuevas empresas de inserción (cinco de las cuales se registran en 2010): Ecolínea, Milhistorias, Inserta, Aluciservice, Manuses, Puentes para la Inclusión, Soulem y MTD. 


\begin{tabular}{|c|c|c|c|}
\hline Convocatoria & Líneas subvencionables & $\begin{array}{c}\text { Dotación } \\
\text { (euros) }\end{array}$ & $\begin{array}{l}\text { Concesiones } \\
\text { (BOCM) } \\
\text { (euros) }\end{array}$ \\
\hline $\begin{array}{l}\text { Orden } \\
3236 / 2007 \\
15 / 11 / 2007\end{array}$ & $\begin{array}{l}\text { - Creación y/o mantenimiento de puestos de trabajo de } \\
\text { inserción } \\
\text { - Contratación de técnicos orientación y acompaña- } \\
\text { miento }\end{array}$ & 400.000 & $65.723,78$ \\
\hline $\begin{array}{l}\text { Orden } \\
2663 / 2008 \\
08 / 10 / 2008\end{array}$ & $\begin{array}{l}\text { - Creación y mantenimiento de puestos de trabajo de in- } \\
\text { serción } \\
\text { - Contratación de técnicos orientación y acompaña- } \\
\text { miento } \\
\text { - Contratación de técnicos de producción y comerciali- } \\
\text { zación } \\
\text { - Inversiones fijas afectas a la realización de su objeto } \\
\text { social } \\
\text { - Creación de empresas de inserción }\end{array}$ & 997894,56 & $136.946,09$ \\
\hline $\begin{array}{l}\text { Orden } \\
2791 / 2009 \\
02 / 11 / 2009\end{array}$ & $\begin{array}{l}\text { Entidades Promotoras: } \\
\text { - Contratación de técnicos orientación y acompaña- } \\
\text { miento } \\
\text { Empresas de inserción: } \\
\text { - Creación de Empresas de inserción. } \\
\text { - Creación y/o mantenimiento de puestos de trabajo de } \\
\text { inserción } \\
\text { - Contratación y/o mantenimiento de técnicos orienta- } \\
\text { ción y acompañamiento } \\
\text { - Contratación y/o mantenimiento de técnicos de pro- } \\
\text { ducción y comercialización. } \\
\text { - Inversiones fijas afectas a la realización de su objeto } \\
\text { social. } \\
\text { - Asistencia técnica. }\end{array}$ & 795.000 & $199.968,52$ \\
\hline $\begin{array}{l}\text { Orden } \\
2141 / 2010 \\
07 / 07 / 2010\end{array}$ & $\begin{array}{l}\text { Entidades promotoras: } \\
\text { - Contratación de técnicos orientación y acompaña- } \\
\text { miento } \\
\text { - Proyectos de viabilidad para crear empresas de inser- } \\
\text { ción. } \\
\text { Empresas de inserción: } \\
\text { - Constitución de Empresas de inserción. } \\
\text { - Creación y/o mantenimiento de puestos de trabajo de } \\
\text { inserción } \\
\text { - Contratación y/o mantenimiento de técnicos orienta- } \\
\text { ción y acompañamiento } \\
\text { - Contratación y/o mantenimiento de técnicos de pro- } \\
\text { ducción y comercialización. } \\
\text { - Inversiones fijas afectas a la realización de su objeto } \\
\text { social. } \\
\text { - Asistencia técnica. } \\
\text { Organizaciones representativas de las Empresas de in- } \\
\text { serción: } \\
\text { - Actividades, estudios, publicaciones, presencia en ferias. }\end{array}$ & 600.000 & $509.639,81$ \\
\hline
\end{tabular}

Cuadro 5. Convocatorias de ayudas en la Comunidad de Madrid (2007-2010). Fuente: elaboración propia. 
Estos datos muestran que entre $2003 \mathrm{y}$ 2009 han sido más las empresas de inserción que han cerrado de las que las que se han creado. Se puede explicar por la falta de ayudas durante cuatro años. La continuidad, a partir de 2007, en la convocatoria de subvenciones puede ser fuente de estímulo para que las nuevas entidades promotoras se pongan en marcha, aunque la crisis económica añade incertidumbres de cara al futuro.

\section{Conclusiones}

Las empresas de inserción deben mantenerse fundamentalmente gracias a sus actividades económicas. El sector reclama ayudas y subvenciones, por su condición de instrumento de las políticas activas de empleo y por el beneficio social que se revierte en la sociedad. El término «fondo perdido», en este sentido, no se aplicaría a estas empresas porque son de hecho una inversión del Estado en políticas sociales integradoras.

El discurso de las administraciones públicas, a su vez, asume su responsabilidad de poner en marcha y facilitar mecanismos para que los sectores más desfavorecidos de la sociedad tengan acceso a derechos y bienestar.

La descentralización de las competencias en términos de empleo implica una gran diversidad de políticas a nivel autonómico que, a la larga, se traduce más en desigualdades que en diversidad, imponiendo distintas velocidades al desarrollo de las mismas. Entre las comunidades autónomas existen diferencias como:

1. Los contextos más crudos o más suaves en términos de exclusión social. Los grandes núcleos urbanos ofrecen condiciones para ensayar todas las formas de lucha contra la exclusión; siendo las empresas de inserción un interesante instrumento a tener en cuenta, como modelo de aprendizaje real en el puesto de trabajo. Los contextos de fuerte desarrollo industrial son una oportunidad, porque pueden ofrecer muchas posibilidades de inserción, la existencia de un mundo empresarial más amplio abre también el abanico a la variedad de actividades económicas posibles para las mismas.

2. Se desprende de los datos analizados una desigualdad notable entre las comunidades autónomas, en cuanto a criterios y cuantías, dando como resultado oportunidades muy distintas según el territorio donde se quiere crear y desarrollar una Empresa de Inserción.

3. Algunas comunidades no han empezado a convocar subvenciones. Las empresas de inserción de nueva creación tienen que apoyarse en sus entidades promotoras o en subvenciones para otro tipo de proyectos, o subvenciones privadas que acaban siendo un recurso cada vez más importante para las iniciativas sociales.

La variedad de plazos y dotaciones presupuestarias también son desiguales y crean incertidumbre. La falta de garantía de convocatorias estables con periodicidad clara no permite realizar contrataciones según la necesidad de la empresa de inserción, restando alcance económico y social a los proyectos.

Los avales bancarios representan una carga para las entidades promotoras y para estas empresas, ya que no se suelen cubrir los gastos para tramitarlos, con fuerte repercusión en las modestas economías de la mayoría de estas empresas, teniendo en cuenta que salvo algunas excepciones, nos estamos refiriendo a microempresas.

La consecuencia de las carencias y desigualdades señaladas hace que entidades sociales que podrían optar por ser promotoras de empresas de inserción no se animan a hacerlo, ya que supone un gran compromiso, riesgo o carga sobre otros recursos que obtienen con mucho esfuerzo. En este sentido, muchas entidades pequeñas, ligadas a los territorios, sobre todo en barrios de núcleos urbanos importantes, ven con buenos ojos la posibilidad de crear una empresa de inserción, pero en muchos casos no está a su alcance.

Por último, antes de señalar algunas líneas que podrían ser tenidas en cuenta de cara al futuro, hay que recordar que una gran parte de los fondos para subvencionarlas proceden de fondos europeos, que no durarán para siempre y habrá que ver cómo se van a suplir cuando ya no distribuyan.

Las conclusiones en líneas de propuestas deberían apuntar hacia:

- La implicación de todos los niveles de las administraciones públicas en térmi- 
nos de medidas de fomento a las empresas de inserción.

- La ampliación del marco de medidas de fomento existentes en términos de subvenciones y cláusulas sociales: infraestructuras adecuadas, convenios específicos, difusión y sensibilización.

- La evaluación de los planes y programas en los que se incluyen las empresas de inserción. Se ha encontrado un ejemplo en el País Vasco en 2006 de evaluación conjunta entre la Administración y el sector.
- La necesidad de planes de fomento explícitos, con metas y recursos, evaluables en el tiempo.

- El compromiso de las distintas administraciones públicas de publicar datos que están (o deberían estar) en los registros de empresas de inserción: transparencia y acceso al sector, investigadores, etc.

- Generalización de estudios de impacto de las medidas de fomento para las empresas de inserción a nivel estatal y en cada comunidad autónoma.

\section{Referencias bibliográficas:}

\subsection{Normativa y convocatorias de subvenciones para empresas de inserción}

LEY 44/2007, de 13 de diciembre, para la regulación del régimen de las empresas de inserción.

\subsection{Navarra}

Decreto Foral 130/1999, de 26 de abril, por el que se regulan las ayudas económicas para el desarrollo de los programas de incorporación socio-laboral destinados a personas en situación de exclusión social.

Decreto ForaL 60/2009, de 2 de julio, de modificación del Decreto Foral 130/1999, de 26 de abril, por el que se regulan las ayudas económicas para el desarrollo de los programas de incorporación sociolaboral destinados a personas en situación de exclusión social.

Decreto Foral 26/2002 de 4 de febrero, por el que se modifica el Decreto Foral 130/1999, de 26 de abril, por el que se regulan las ayudas económicas para el desarrollo de los programas de incorporación socio-laboral destinados a personas en situación de exclusión social.

\subsubsection{Aragón}

Decreto 33/2002 de 5 de febrero, del Gobierno de Aragón, por el que se regulan las Empresas de inserción Laboral y se aprueba el Programa ARINSER de ayudas económicas para la integración socio-laboral de colectivos en situación o riesgo de exclusión.

Decreto 37/2006 de 7 de febrero, del Gobierno de Aragón, por el que se regulan las Empresas de inserción Laboral y se aprueba el Programa ARINSER de ayudas económicas para la integración socio-laboral de colectivos en situación o riesgo de exclusión.

Orden de 14 de marzo de 2006, del Departamento de Economía, Hacienda y Empleo, por la que se convocan para el año 2006 las ayudas del Programa ARINSER, establecidas en el Decreto 37/2006, de 7 de febrero, del Gobierno de Aragón, por el que se regulan las Empresas de inserción Laboral y se aprueba el Programa ARINSER de ayudas económicas para la integración socio-laboral de colectivos en situación o riesgo de exclusión.

Orden de 28 de febrero de 2008, del Departamento de Economía, Hacienda y Empleo, por la que se convocan para el año 2008 las subvenciones del programa ARINSER, establecidas en el Decreto 37/2006, de 7 de febrero, del Gobierno de Aragón, por el que se regulan las Empresas de inserción Laboral y se aprueba el Programa ARINSER de ayudas económicas para la integración socio-laboral de colectivos en situación o riesgo de exclusión.

Decreto 128/2009 de 21 de julio, del Gobierno de Aragón por el que se regula el régimen de las empresas de inserción y el procedimiento para su calificación y registro en la Comunidad Autónoma de Aragón.

Resolución de 18 de febrero de 2010, de la Dirección Gerencia del Instituto Aragonés de Empleo, por la que se convocan para el año 2010 las subvenciones del Programa ARINSER, para la in- 
tegración socio-laboral de personas en situación o riesgo de exclusión a través de empresas de inserción.

Orden de 19 de enero de 2011, por la que se modifican diversos artículos de la Orden de 31 de julio de 2009, del Departamento de Economía, Hacienda y Empleo, por la que se aprueba el Programa ARINSER y se establecen las bases reguladoras para la concesión de subvenciones contempladas en el mismo para la integración socio-laboral de personas en situación o riesgo de exclusión a través de empresas de inserción.

Resolución de 25 de febrero de 2011, de la Dirección Gerencia del Instituto Aragonés de Empleo, por la que se convocan para el año 2011 las subvenciones del Programa ARINSER, para la integración socio-laboral de personas en situación o riesgo de exclusión a través de empresas de inserción.

\subsubsection{País Vasco}

Decreto 305/2000, de 26 de diciembre, por el que se regula la calificación de las empresas de inserción, se establece el procedimiento de acceso a las mismas y se crea el registro de empresas de inserción.

Orden de 11 de diciembre de 2002, Consejero de Justicia, Empleo y Seguridad Social de modificación de la Orden por la que se regulan las ayudas para la incorporación de socios/as a empresas de Economía Social.

Orden de 12 de marzo de 2003, Consejero de Justicia, Empleo y Seguridad Social por la que se realiza para el presente año la convocatoria de las ayudas previstas en la orden de 11 de diciembre de 2002, por la que se regulan las ayudas a la creación y el sostenimiento de las empresas de inserción

Orden de 31 de marzo de 2004, Consejero de Justicia, Empleo y Seguridad social por la que se realiza para el presente año la convocatoria de las ayudas previstas en el decreto 303/2000, de 26 de diciembre, por el que se regula el programa junior-empresa

Orden de 13 de abril de 2005, Consejero de Justicia, Empleo y Seguridad social por la que se realiza para el presente año la convocatoria de las ayudas previstas en la orden de 11 de diciembre de 2002, por la que se regulan las ayudas para la creación y el sostenimiento de las empresas de inserción

Decreto 182/2008 de 11 de noviembre, por el que se regula la calificación de empresas de inserción, se establece el procedimiento de acceso a las mismas y su registro.

Orden de 30 de abril de 2010, Consejera de Empleo y Asuntos Sociales por la que se realiza para el presente año la convocatoria de las ayudas previstas en la Orden de 4 de mayo de 2009, por la que se regulan las ayudas para la creación y el sostenimiento de las empresas de inserción

\subsubsection{Cataluña}

Ley 27/2002 de 20 de diciembre, de Medidas Legislativas para Regular las Empresas de inserción Sociolaboral.

Decreto 277/2003 de funcionamiento y competencia del Registro administrativo de empresas de inserción de Cataluña.

Ley 15/2005, de 27 de diciembre, de reforma parcial de diversos preceptos legales en materias de agricultura, ganadería y pesca, de comercio, de salud y de trabajo (Art. 9) De modificación de la Ley 27/2002, del artículo 4b, de la Ley 27/2002, de 20 de diciembre, sobre medidas legislativas para regular las empresas de inserción sociolaboral.

Ley 44/2007, de 13 de diciembre, para la regulación del régimen de las empresas de inserción.

Resolución TRI/313/2006 por la que se abre la convocatoria para el año 2006 para la concesión de subvenciones para la inserción laboral de las personas acogidas a la renta mínima de inserción a través de empresas de inserción sociolaboral, entidades colaboradoras de inserción $y$ proyectos de autoocupación (código de reserva $Z 26$ ).

Orden TRE/860/2008 de 17 de marzo, por la que se hace pública la convocatoria del año 2008 para la concesión de subvenciones para la inserción laboral de las personas acogidas a la ren- 
ta mínima de inserción mediante empresas de inserción sociolaboral, entidades colaboradoras de inserción y proyectos de autoocupación.

Resolución TRE/2083/2008 de fijación del importe máximo destinado a determinadas ayudas y subvenciones previstas en la Orden TRE/267/2008, de 22 de mayo, por la que se aprueban las bases reguladoras para la concesión de ayudas y subvenciones a los programas de igualdad de oportunidades en el trabajo: programas para la diversidad.

Resolución TRE/805/2009 de 15 de mayo, por la que se modifican los importes máximos destinados a la concesión de subvenciones que prevé la Resolución TRE/805/2009, de 13 de marzo

Orden TRE/509/2009 de 2 de noviembre, por la que se aprueban las bases reguladoras para la concesión de ayudas y subvenciones a los programas de igualdad de oportunidades en el trabajo: programas laborales para la diversidad.

Orden TRE/113/2010 de 22 de febrero, que modifica la Orden TRE/509/2009, de 2 de noviembre, por la que se aprueban las bases reguladoras para la concesión de ayudas y subvenciones a los programas de igualdad de oportunidades en el trabajo: programas laborales para la diversidad, y se fija el importe máximo de determinadas ayudas y subvenciones previstas en la misma Orden.

\subsubsection{Canarias}

Decreto 32/2003_ de 10 de marzo, por el que se regula la inserción sociolaboral en empresas de inserción.

Orden de 13 de septiembre de 2004, por la que se desarrolla el Decreto 32/2003, de 10 de marzo, que regula la inserción sociolaboral en empresas de inserción.

Resolución de 11 de septiembre de 2008, del Director, por la que se resuelve la convocatoria de subvenciones públicas dirigidas a la inserción sociolaboral en empresas de inserción del año 2009.

Resolución de 27 de abril de 2009 del Presidente, por la que se establece la convocatoria y se determinan los importes de los créditos destinados a la concesión de subvenciones dirigidas a la inserción sociolaboral en empresas de inserción para el ejercicio 2009.

Decreto 137/2009 de 20 de octubre, por el que se regula la calificación de empresas de inserción, el procedimiento de acceso a las mismas y el Registro de Empresas de inserción.

Resolución de 29 de junio de 2010, de Subvenciones 2010. Dirigidas a la Inserción Sociolaboral en Empresas de inserción, en el marco del Plan Canarias Emplea, incluidas en la Programación 2010, cofinanciadas por el Fondo Social Europeo.

\subsubsection{Comunidad de Madrid}

Decreto 32/2003 de 13 de marzo, del Consejo de Gobierno, por el que se regula la colaboración de las empresas de promoción e inserción laboral de personas en situación de exclusión social con la Comunidad de Madrid y se establecen medidas de fomento de su actividad.

Orden 2580/2003, de 6 de junio, del Consejero de Trabajo, por la que se regula la organización y funcionamiento del Registro Administrativo de Empresas de Promoción e Inserción Laboral de Personas en Situación de Exclusión Social subvencionables por la Comunidad de Madrid.

Orden 2581/2003, de 6 de junio, de la Consejería de Trabajo, por la que se regulan las ayudas a las empresas de promoción e inserción laboral de personas en situación de exclusión social de la Comunidad de Madrid para el año 2003.

Orden 3236/2007, de la Consejería de Empleo y Mujer por la que se aprueban las bases reguladoras de las subvenciones que se concedan a las Empresas de Promoción e Inserción Laboral para la inserción laboral de personas en situación de exclusión social de la Comunidad de Madrid, cofinanciadas por el Fondo Social Europeo, y se establece la convocatoria para el año 2007.

Orden 2663/2008, de 26 de septiembre de la Consejería de Empleo y Mujer, por la que se modifica la Orden 3236/2007, de 5 de noviembre, por la que se aprueban las bases reguladoras de las subvenciones que se concedan a las Empresas de Promoción e Inserción Laboral para la inserción laboral de las personas en situación de exclusión social de la Comunidad de Madrid, cofinanciadas por el Fondo Social Europeo, y se establece la convocatoria para el año 2008. 
Orden 2791/2009, de 20 de octubre, de la Consejería de Empleo y Mujer, por la que se aprueban las bases reguladoras de las subvenciones que se concedan a las Empresas de inserción Laboral para la inserción laboral de las personas en situación de exclusión social de la Comunidad de Madrid, cofinanciadas por el Fondo Social Europeo, y se establece la convocatoria para el año 2009.

Orden 2141/2010, Consejería de Empleo, Mujer e Inmigración de 17 de junio, por la que se aprueban las bases reguladoras de las subvenciones que se concedan a las empresas de inserción, entidades promotoras y entidades representativas para la inserción laboral de las personas en situación de exclusión social de la Comunidad de Madrid, cofinanciadas por el Fondo Social Europeo, y se establece la convocatoria para el año 2010.

\subsubsection{La Rioja}

LEY 7/2003 de 26 de marzo, de Inserción Sociolaboral.

Decreto 2/2006 de 13 de enero, por el que se crea el Registro de Empresas de inserción Sociolaboral de La Rioja y se regulan los requisitos para la calificación e inscripción en dicho Registro.

Orden de 19 de enero de 2006, Consejería de Hacienda y Empleo, por la que se regula la organización y funcionamiento del registro de empresas de inserción de La Rioja y el procedimiento de calificación e inscripción.

Orden de 25 de septiembre de 2007, Consejería de Industria, Innovación y Empleo , por la que se establecen las bases reguladoras para la concesión de ayudas al fomento del empleo de personas en situación o grave riesgo de exclusión sociolaboral en Empresas de inserción.

\subsubsection{Islas Baleares}

Decreto 60/2003 de 13 de junio, por el que se regula la calificación de las iniciativas empresariales de inserción y se crea el Registro de Iniciativas Empresariales de Inserción de las Illes Balears.

\subsection{Murcia}

Orden de 2 de enero del año 2004, de la Consejería de Trabajo, Consumo y Política Social, sobre ayudas para programas de inserción.

Orden de 20 de junio de 2007, de la Presidenta del Servicio Regional de Empleo y Formación, por la que se aprueban las bases reguladoras de los programas de subvenciones para el fomento de las empresas de inserción.

Resolución de 27 de julio de 2007 del director general del Servicio Regional de Empleo y Formación, por la que se aprueba la convocatoria para la concesión de subvenciones del programa: "empresas de inserción», correspondientes al ejercicio 2007.

Resolución de 19 de septiembre de 2008, del Director General del Servicio Regional de Empleo y Formación, por la que se aprueba la convocatoria de subvenciones del programa «Empresas de inserción», correspondiente al ejercicio 2008.

Orden de 31 de julio de 2008, Presidente del Servicio Regional de Empleo y Formación, de modificación parcial de la Orden de 20de junio de 2007, por la que se aprueban las bases reguladoras de los programas de subvenciones para el fomento de las empresas de inserción.

Resolución de 18 de mayo de 2010, Director General Servicio Regional de Empleo y Formación por la que se aprueba la convocatoria de subvenciones del programa «empresas de inserción», correspondiente al ejercicio 2010.

\subsubsection{Comunidad Valenciana}

Ley $1 / 2007$ de 5 de febrero, de la Generalitat, por la que se regulan las empresas de inserción para fomentar la inclusión social en la Comunitat Valenciana.

Decreto 81/2009 de 12 de junio, del Consell, por el que se dictan normas de desarrollo para la calificación, registro y fomento de las empresas de inserción en la Comunitat Valenciana. 
Orden 31/2010 de 30 de julio, de la Consellería de Economía, Hacienda y Empleo, por la que se convoca y regula la concesión de subvenciones públicas destinadas a la integración sociolaboral de trabajadores en situación o riesgo de exclusión social en empresas de inserción y en empresas ordinarias de trabajo para el ejercicio 2010.

\subsubsection{Castilla y León}

Decreto 34/2007 de 12 de abril, por el que se regula el procedimiento de calificación de las empresas de inserción laboral y se crea su registro administrativo.

Orden EYE/553/2009 de 6 de marzo, por la que se establecen las bases reguladoras de las subvenciones públicas destinadas a la financiación de los costes salariales de los trabajadores en situación o riesgo de exclusión social en las empresas de inserción.

Orden EYE/618/2009, de 13 de marzo, por la que se convocan subvenciones públicas destinadas a la financiación de los costes salariales de los trabajadores en situación o riesgo de exclusión social en las empresas de inserción para el año 2009.

Orden EYE/1371/2010 de 30 de septiembre, por la que se establecen las bases reguladoras de las subvenciones destinadas a la financiación de la contratación de personas con discapacidad o en situación o riesgo de exclusión social, así como desempleados en general, en Centros Especiales de Empleo y en Empresas de inserción publicada en el Boletín Oficial de Castilla y León.

\subsubsection{Galicia}

Decreto 156/2007 de 19 de julio, por el que se regula el procedimiento para la calificación de las empresas de inserción laboral, se crea su registro administrativo y se establecen las medidas para el fomento de la inserción sociolaboral.

Orden de 6 de mayo de 2008 por la que se regula el procedimiento de calificación de las empresas de inserción laboral y la organización y funcionamiento de su registro administrativo.

Orden de 16 de julio de 2008 por la que se establece el programa de incentivos a las empresas de inserción laboral (E.I.L.) cofinanciado por el fondo social europeo, y se procede a su convocatoria para el año 2008.

Orden de 30 de diciembre de 2008 por la que se establecen las bases reguladoras del programa de incentivos a las empresas de insercion laboral (EIL) cofinanciado por el Fondo Social Europeo, y se procede a su convocatoria para el año 2009.

Orden de 26 de mayo de 2010 de la Conselleria de Trabajo y Bienestar (Xunta de Galicia), por la que se establecen las bases reguladoras del programa de incentivos a las empresas de inserción laboral (EIL), cofinanciado por el Fondo Social Europeo, y se procede a su convocatoria para el año 2010.

\subsubsection{Principado de Asturias}

Resolución de 22 de diciembre de 2008 de la Consejería de Industria y Empleo, por la que se establece el Registro de Empresas de inserción del Principado de Asturias.

\subsubsection{Extremadura}

Decreto 78/2010 de 18 de marzo, por el que se regula el procedimiento para la calificación de las empresas de inserción laboral y la creación del Registro de Empresas de inserción de la Comunidad Autónoma de Extremadura.

\subsubsection{Castilla- La Mancha}

Decreto 22/2010 de 20/04/2010, por el que se dictan normas de desarrollo para la calificación de empresas de inserción y se crea el registro administrativo de estas empresas.

\subsubsection{Andalucía}

Decreto 193/2010 de 20 de abril, por el que se regula la calificación y se crea el Registro de Empresas de inserción en Andalucía. 


\subsection{Informes, estudios y publicaciones}

Basagoiti Rodríguez, M. (1998). Las Empresas de inserción en la Comunidad de Madrid. Inédito. Cáritas Española (1999). Las Empresas de inserción a Debate. Documentación Social, 117118.(Monografía).

FEDEI (2003). Identificación y Diagnóstico de las Empresas de inserción en España. Madrid: Federación Española de Entidades de Empresas de inserción.

AMEI (2008). Memoria Social 2007 de las Empresas de inserción en la Comunidad de Madrid. AMEI (2009). Memoria Social 2008 de las Empresas de inserción en la Comunidad de Madrid. AMEI (2010). Memoria Social 2009 de las Empresas de inserción en la Comunidad de Madrid. FAEDEI (2010). Memoria Social 2009 de las Empresas de inserción en España. 